\title{
Assessment of Consumers Acceptance of E-Commerce to Purchase Geographical Indication Based Crop Using Technology Acceptance Model (TAM)
}

\author{
Darryl Jeethesh D'souza ${ }^{1}$, Harisha G. Joshi², Raghavendra Prabhu ${ }^{1}$ \\ ${ }^{1}$ School of Information Sciences, Manipal Academy of Higher Education, India \\ ${ }^{2}$ School of Management, Manipal Academy of Higher Education, India
}

\begin{abstract}
Diffusion of Information and Communication Technology (ICT) in every aspect of life has made the applications of e-commerce a fundamental part of marketing. Hence using e-commerce to market Geographical Indication (GI) based crops is quite essential for the survival of the growers associated with such crops. Due to this significance, it is critical to assess consumers acceptance of e-commerce to purchase geographical indicationbased crop. The study uses Technology Acceptance Model (TAM) to validate consumers' willingness of using e-commerce to purchase GI crops with specific reference to Udupi jasmine. To analyse the relationships between TAM variables, Structural Equation Modelling (SEM) technique was adopted. The analysis suggests that behavioural intentions of consumers will influence them into actual e-commerce use. Behavioural intention exerts a significant positive influence on the actual e-commerce use suggests that, if provided with an e-commerce application to purchase the product online, consumers are likely to accept and use it.
\end{abstract}

\section{Keywords}

Technology Acceptance Model (TAM), Structural Equation Modelling (SEM), e-commerce, Geographical Indication (GI), Information and Communication Technology (ICT).

D'souza, D. J., Joshi, H. G. and Prabhu, R. (2021) “Assessment of Consumers Acceptance of E-Commerce to Purchase Geographical Indication Based Crop Using Technology Acceptance Model (TAM)", AGRIS on-line Papers in Economics and Informatics, Vol. 13, No. 3, pp. 25-33. ISSN 1804-1930. DOI 10.7160/aol.2021.130303.

\section{Introduction}

Acceptance of technology is a critical factor for any technology to thrive. In general, acceptance is defined as "the process or fact of being received as adequate, valid, or suitable". Factors that influence user's decision to use a particular system must be considered by decision makers. This would help greatly during the development phase of an application. "Why people accept new technologies?" is a common question of researchers, technocrats, developers etc. and answer to this question may help them to build better methods for designing, evaluating, and predicting the response of the users to the new technologies (Dillon and Morris, 1996). The application of Technology Acceptance Models (TAM) and theories have been used in various domains to understand and predict user's behavior.

Internet technology today has been adopted by many people in their personal and, in their professional life. To gauge people's intention to use e-commerce web application to buy a Geographical Indication (GI) based crop online, one can use certain theoretical models. The theories put forward indicates the factors that will influence the intentions of using technology. The constructs of the model may vary based on the objectives of the research. While analysing people's intention to shop online, Technology Acceptance Model is widely used (Ha and Stoel, 2009; Hassan and Al-Alnsari, 2010). Chuttur (2009) says that while modelling approach in IT research, TAM has captured the most attention of the scientific community. Gefen and Straub (2000) remarks that while predicting information technology adoption TAM is most widely researched models, while Agarwal and Prasad (1997) assert that TAM has been widely accepted among information systems researchers, due to its sumptuous and a great deal of empirical support for it in recent years.

A lot of TAM research has been done 
in the aspect of IT acceptance of work-related activity and the theory can also be successfully applied to various non-organizational settings (Argawal and Karahanna, 2000), which also includes e-commerce (Gefen \& Straub, 2000; Lederer et al., 2000). The practicality, effectiveness and feasibility of TAM has been shown in several empirical studies. Gefen and Straub (2000) while taking amazon. com as an example analyses a user's behaviour towards the intention to using e-commerce website based on the TAM. While taking MBA students in a commercial college as respondents to carry out the empirical study. They ascertain that PEOU does not affect behavioural intention in a purchasing task but affects behavioural intention in an inquiry task and purchasing something on the website PEOU will affect PU and in turn, PU will affect behavioural intention.

While explaining the consumer's acceptance of shopping online Lin and Lu (2000) asserts that the researcher can use TAM to explain this behaviour. They demonstrate PEOU exerts an indirect influence on behaviour intention through PU and does not have a direct effect on behaviour intention. While studying online shoppers O'Cass and Fenech (2003) validates the application of TAM on retail e-commerce. They determine that PU and PEOU has positive correlation with the attitude of online shopping. It has been proved effective to use TAM to study consumer's attitude towards behaviour intention of using e-commerce and is used widely. Babin and Babin (2001) shows that consumers who feel adept at using online sales or e-commerce systems will have a desire or intention to purchase.

A number of review of literature shows that TAM studies have been applied in e-commerce sites that are selling books (Gefen and Straub, 2000), transactional web sites (Aladwani, 2002), technological fields (Schepers and Wetzels, 2007) etc. From the various related research shown above, while predicting the personal acceptance of use technology TAM has mostly been widely accepted, used and deployed. From the aspect of e-commerce website, TAM constructs usefulness and convenience of use affects the consumer decision to conduct a transaction and are a major factor that affects the use of the website (Syarifudin et al., 2018).

D'souza and Joshi (2019) suggested that an e-commerce framework specific to market GI based crops would prove highly beneficial. Based on this framework an e-commerce web application was built to test willingness of consumers in using e-commerce to buy GI based crop (D'souza and Joshi 2020). Hence to assess consumers acceptance of e-commerce to purchase geographical indication-based crop TAM was used. This would help in understanding the user acceptance of e-commerce web application and further validate the framework proposed by D'souza and Joshi (2019). Structural Equation Modelling (SEM) was employed to analyze the relationships between various TAM constructs.

\section{Materials and methods}

It is critical for an e-commerce project to effectively deliver information to the key stake holders. The study uses TAM to validate consumers' willingness of using e-commerce to purchase GI based crops with specific reference to Udupi jasmine. The study uses the e-commerce test web application build using the e-commerce framework proposed by D'souza and Joshi (2020). An essential part of the development of any survey involves the process of framing a questionnaire, determination of the list of questions and designing the format of either written or printed questionnaire (Zikmund, 2003). A questionnaire was designed to cover necessary factors needed for the acceptance of the model among consumers. A pilot study was conducted to this effect and based on the pilot study the questionnaire was refined and modified. While doing so expert opinion was also incorporated for the validation. The questionnaire contained questions on a 5-point Likert scale regarding the different constructs of TAM scales namely Perceived Usefulness (PU), Perceived Ease of Use (PEOU), Behavioural Intention (BI) and E-commerce Use (EU) and the same are shown in Table 1. Assessment of TAM variables PU, PEOU, BI and EU measured by considering 6 items for PU, 4 items for PE, 3 items for BI and 2 items for EU.

The primary target was the general public who were the consumers of the product. Data was collected through a structured questionnaire by adopting a personal interview technique. Personal interview technique was used as the respondents needed assistance to understand the questions in their local language generally Tulu and Kannada for both Udupi taluk and Mangalore. A total of 122 respondents from Mangalore and Udupi were interviewed based on quota sampling technique, the most important sample in the group of non-probabilistic samplings. By logic, quota 
sampling is the closest to probabilistic sampling from all non-probabilistic sampling techniques (Yang and Banamah, 2014). The challenge of validation of the developed e-commerce model was met by face-to-face interaction with the selected buyers from both Mangalore and Udupi market. Even though it was a difficult proposition, the fieldwork was done in a justifiable manner with the purpose of understanding the response of the buyers. The sample was chosen among the consumers with the condition that the chosen respondent shall be a buyer of the specific GI product and has familiarity with online shopping.

Test-retest and internal consistency are the two factors employed by this study to ensure reliability (Cooper and Schindler, 2016). Test-retest method was used on a small scale of twenty respondents representing agents and fifteen respondents representing consumers, twice in a period of twenty days. The consistency in the responses given between the two measures are the indicators of a high degree of reliability (Zikmund, 2003). Cronbach's
Alpha Coefficient was used as a measure to test reliability. The closer Cronbach's alpha is to 1, the higher the internal consistency reliability (Sekaran and Bougie 2016). For TAM variables the value of 0.75 (for perceived usefulness), 0.73 (for perceived ease of use) and 0.76 (for behavioural intentions) respectively. As determining whether a measure sufficiently covers a content area is not possible through a statistical test, hence content validity usually depends on the judgment of experts in the field (Zikmund, 2003). Hence the validity was determined by experts in the field and changes were incorporated accordingly based on the suggestions. Data collected from the questionnaire administered to the consumers were post-coded and were taken down using a five-point Likert scale with the format of 1 - Strongly disagree, 2 - Disagree, 3 - Neither agree nor disagree, 4 - Agree, 5 - Strongly agree. Coding is done so that the data can be transformed to be suitable for computer-aided analysis (Table 1).

To analyse the relationships between PU, PEOU,

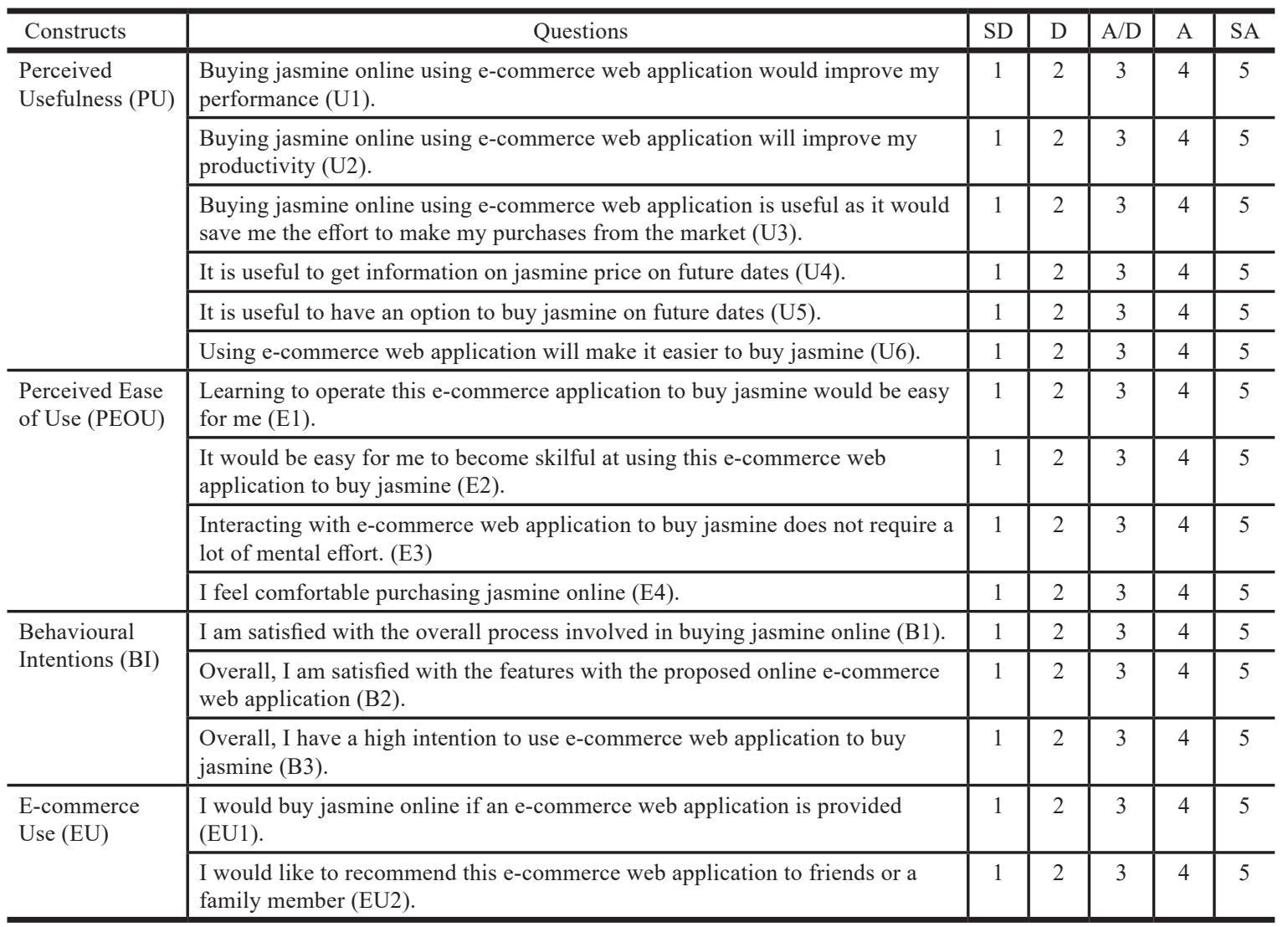

Note:Strongly Disagree (SD) - 1, Disagree (D) - 2, Neither Agree nor Disagree (A/D) - 3, Agree (A) - 4, Strongly Agree (SA) - 5

Source: own research and processing

Table 1: TAM variables PU, PEOU, BI and EU measured by considering 6 items for PU, 4 items for PE, 3 items for BI and 2 items for $\mathrm{EU}(\mathrm{N}=122)$. 
BI and EU in TAM, Structural Equation Modelling (SEM) technique was adopted. While dealing with the latent (unobserved) variables of constructs and their indicators (observed) variables Measurement model comes in handy. It focuses on the link between factors and their measured variables. "SEM technique is preferred for developing complex models. Various types of hypothesized models can be tested using SEM" (Schumacker and Lomax, 2010). For simultaneous estimation of a series of separate multiple regression techniques, SEM is the most efficient estimation technique (Joseph et al., 2010). Measurement model (CFA) and Structural models are components of SEM. The advantage of a structural model is that it allows the researcher to test the predicted relationships between independent and dependent variables. While using SEM the researcher can test the entire theoretical model in one analysis, unlike many other statistical techniques.

As TAM variables are inter-related, SEM is expressed using path analysis with model fit indices. Model fit determines the degree to which the SEM fits the sample data. While considering what constitutes an adequate fit there are no wellestablished guidelines. But the general approach is to establish that the model is identified, there is a convergence in the iterative estimation procedure, all estimated parameters are well within the range of permissible values, and that the estimated parameters standard errors have reasonable size (Marsh and Grayson, 1995).

There is no single statistical test in SEM that can best describe the strength of the model's prediction. Instead, researchers have developed different types of measures, in combination to assess the results. To asses, the model researchers use numerous goodness-of-fit indicators with reference to model fit. In SEM, ensuring the model fit is the most crucial step. According to Joseph et al., (2010) specific indices are Chi-square Mean/Degree of Freedom (CMIN/DF), Normed Fit Index (NFI), Goodness of Fit (GFI), Root Mean Square Error of Approximation (RMSEA), Adjusted Goodness of Fit (AGFI), and Comparative Fit Index (CFI). The wellness of different indices with different samples sizes, types of data, and ranges of acceptable scores are the major factors to decide whether a good fit exists. Hence based on the values of the fit indices a goodness of fit is established between TAM variables. Analysis of Moment Structures (AMOS) trail version was used to conduct SEM. Statistical significance was set at $\mathrm{p}$-value $<0.005$. A p-value of 0.05 , a commonly used threshold, means that there is a 5\% chance of achieving those results without there being a real effect. A p-value of 0.005 means there is only a $0.5 \%$ chance of result without having an actual effect (Johnson, 2013).

\section{Results and discussion}

TAM variables were measured by considering 6 items for PU, 4 items for PE, 3 items for BI and 2 items for EU and these items were measured using 5-point Likert scale. The same are presented in Annexure 1. The assessment of TAM variables is shown in Table 2.

Overall, each of the variables were measured by averaging the responses of respondents and assessment was drawn based on the following category:

- If the mean value is less than 2 not at all useful.

- If less than 3 not useful.

- $\quad$ If more than 4 highly useful.

\section{Perceived Usefulness (PU)}

Assessment of PU from table shows that respondents strongly agree for item U1 with mean of $4.02 \pm 0.9$. Similarly, respondents strongly agree for items $\mathrm{U} 4, \mathrm{U} 5$, U6 with mean of $4.46 \pm 0.62,4.57 \pm 0.56$ and $4.23 \pm 0.74$ respectively. Whereas they agree for the item U2 and U3 with mean of $3.56 \pm 0.89$ and $3.97 \pm 0.66$. Overall PU was found very high among respondents with a mean of $4.13 \pm 0.51$.

\section{Perceived Ease of Use (PEOU)}

Assessment of PEOU from table shows that respondents strongly agree for item E3 and E4 with mean of $4.64 \pm 0.61$ and $4.49 \pm 0.50$. whereas they agree for items E1 and E2 with mean of $3.74 \pm 0.73$ and $3.98 \pm 0.72$ respectively. Overall PEOU was found very high among respondents with a mean of $4.21 \pm 0.50$.

\section{Behavioural Intention (BI)}

Assessment of BI from table shows that respondents strongly agree for items B1 and B3 with mean of $4.20 \pm 0.73$ and $4.54 \pm 0.62$. whereas they agree for item B3 with mean of $3.98 \pm 0.72$. Overall BI was found very high among respondents with a mean of $4.24 \pm 0.50$.

\section{E-commerce Use (EU)}

Assessment of EI from table shows that respondents strongly agree for items E1 and E2 with mean of $4.49 \pm 0.57$ and $4.59 \pm 0.50$. Overall EI was 
found very high among respondents with a mean of $4.54 \pm 0.47$.

\section{Structural Equation Modelling using path analysis}

Structural Equation Modelling (SEM) was used to assess the goodness of fit between TAM variables and simultaneously analyse the paths in the model. As TAM variables are inter-related, SEM is expressed using path analysis with latent variables. To examine the causal relationships among all constructs, the proposed structural model was tested using SEM. The SEM model fitted between PU, PEOU, BI and EU showed reasonably good model fit according to multiple SEM fit statistics. Results of multiple SEM fit statistics are shown in Table 3. Because there is no single statistical significance test that identifies a correct model given the sample data, it is necessary to take multiple criteria into consideration and to evaluate model fit on the basis of various measures simultaneously.

The structural model for consumer attitude towards e-commerce usage is shown in Figure 1.

The value and analysis of each goodness-of-fit indices is presented as follows:

The value of CMIN/DF $=1.858$ where cut-off for good fit must be $<2$. Researchers have suggested a value between 1 and 5 is appropriate for chi-square/df. Though a value less than 3 is considered good fit. The value of GFI $=0.874$, AGFI $=0.864$ where cut-off for good fit must be $>0.85$. GFI greater than 0.85 and AGFI greater than 0.8 are acceptable (Joseph et al., 2010). The value of NFI $=0.970$ where cut-off for good fit must be $>0.95$. For NFI value greater than 0.9 are recommended whereas, values greater than 0.80 are also acceptable (Joseph et al., 2010). The value of CFI $=0.931$ where cut-off for good fit must be $>0.90$. CFI value should be greater than 0.90 . The value of RMSEA $=0.119$ where cut-off for good fit must be $<1$. RMSEA value below 1 indicates a good fit (Joseph et al., 2010).

As all the values fall within the desired range represent a good fitting model. The path diagram and the table showed that relation between PU and PEOU is significant and positive with $\beta=0.48, p=0.001$. Further there is significant and positive impact of $\mathrm{PU}(\beta=0.37, \mathrm{p}=0.011)$ and PEOU $(\beta=0.56, p=0.000)$ on BI. In turn BI has significant positive impact on EU with $\beta=0.68$, $\mathrm{p}=0.000<0.01$. The analysis from SEM suggest that behavioural intentions of consumers will impact in actual E-Commerce use. It is interesting

\begin{tabular}{|c|c|c|c|c|c|c|c|}
\hline & 1 & 2 & 3 & 4 & 5 & \multirow{2}{*}{ Mean } & \multirow{2}{*}{ Std. Deviation } \\
\hline & Row N \% & Row N \% & Row N \% & Row N \% & Row N \% & & \\
\hline U1 & $.0 \%$ & $3.3 \%$ & $29.5 \%$ & $29.5 \%$ & $37.7 \%$ & 4.02 & .90 \\
\hline $\mathrm{U} 2$ & $.0 \%$ & $9.8 \%$ & $41.0 \%$ & $32.8 \%$ & $16.4 \%$ & 3.56 & .89 \\
\hline U3 & $.0 \%$ & $.0 \%$ & $23.0 \%$ & $57.4 \%$ & $19.7 \%$ & 3.97 & .66 \\
\hline U4 & $.0 \%$ & $.0 \%$ & $6.6 \%$ & $41.0 \%$ & $52.5 \%$ & 4.46 & .62 \\
\hline U5 & $.0 \%$ & $.0 \%$ & $3.3 \%$ & $36.1 \%$ & $60.7 \%$ & 4.57 & .56 \\
\hline U6 & $.0 \%$ & $1.6 \%$ & $13.1 \%$ & $45.9 \%$ & $39.3 \%$ & 4.23 & .74 \\
\hline \multicolumn{6}{|c|}{ Perceived usefulness } & 4.13 & .51 \\
\hline E1 & $.0 \%$ & $3.3 \%$ & $32.8 \%$ & $50.8 \%$ & $13.1 \%$ & 3.74 & .73 \\
\hline E2 & $.0 \%$ & $.0 \%$ & $26.2 \%$ & $49.2 \%$ & $24.6 \%$ & 3.98 & .72 \\
\hline E3 & $.0 \%$ & $.0 \%$ & $6.6 \%$ & $23.0 \%$ & $70.5 \%$ & 4.64 & .61 \\
\hline E4 & $.0 \%$ & $.0 \%$ & $.0 \%$ & $50.8 \%$ & $49.2 \%$ & 4.49 & .50 \\
\hline \multicolumn{6}{|c|}{ Perceived Ease of Use } & 4.21 & .50 \\
\hline B1 & $.0 \%$ & $.0 \%$ & $18.0 \%$ & $44.3 \%$ & $37.7 \%$ & 4.20 & .73 \\
\hline B2 & $.0 \%$ & $.0 \%$ & $26.2 \%$ & $49.2 \%$ & $24.6 \%$ & 3.98 & .72 \\
\hline B3 & $.0 \%$ & $.0 \%$ & $6.6 \%$ & $32.8 \%$ & $60.7 \%$ & 4.54 & .62 \\
\hline \multicolumn{6}{|c|}{ Behavioural Intentions } & 4.24 & .50 \\
\hline EU1 & $.0 \%$ & $.0 \%$ & $3.3 \%$ & $44.3 \%$ & $52.5 \%$ & 4.49 & .57 \\
\hline EU2 & $.0 \%$ & $.0 \%$ & $.0 \%$ & $41.0 \%$ & $59.0 \%$ & 4.59 & .50 \\
\hline \multicolumn{6}{|c|}{ E-commerce Use } & 4.54 & .47 \\
\hline
\end{tabular}

Source: own research and processing

Table 2: Summary of percentage, mean and standard deviations for TAM variables. 


\begin{tabular}{|c|c|c|c|c|c|}
\hline & Path & & Estimate & p-value & Model Fit Indices \\
\hline $\mathrm{U}$ & $<---$ & E & .483 & .001 & \multirow{19}{*}{$\begin{array}{c}\mathrm{CMIN} / \mathrm{DF}=1.858 \\
\mathrm{GFI}=0.874 \\
\mathrm{AGFI}=0.864 \\
\mathrm{NFI}=0.970 \\
\mathrm{CFI}=0.931 \\
\mathrm{RMSEA}=0.11\end{array}$} \\
\hline B & $<---$ & $\mathrm{U}$ & .373 & .011 & \\
\hline B & $<---$ & E & .556 & .000 & \\
\hline EU & $<---$ & B & .680 & .010 & \\
\hline U1 & $<---$ & U & .780 & .000 & \\
\hline U2 & $<--$ & U & .778 & .000 & \\
\hline U3 & $<--$ & U & .661 & .000 & \\
\hline $\mathrm{U} 4$ & $<--$ & $\mathrm{U}$ & .714 & .000 & \\
\hline U5 & $<--$ & $\mathrm{U}$ & .720 & .000 & \\
\hline U6 & $<--$ & $\mathrm{U}$ & .624 & .000 & \\
\hline E3 & $<--$ & $\mathrm{E}$ & .787 & .000 & \\
\hline E2 & $<--$ & E & .801 & .000 & \\
\hline E1 & $<---$ & E & .765 & .000 & \\
\hline E4 & $<---$ & E & .856 & .000 & \\
\hline B1 & $<---$ & B & .774 & .000 & \\
\hline B2 & $<---$ & B & .575 & .000 & \\
\hline B3 & $<---$ & B & .507 & .000 & \\
\hline EU2 & $<--$ & EU & .543 & .000 & \\
\hline EU1 & $<--$ & $\mathrm{EU}$ & 1.0151 & .002 & \\
\hline
\end{tabular}

Source: own research and processing

Table 3: Standardized Regression Weights.

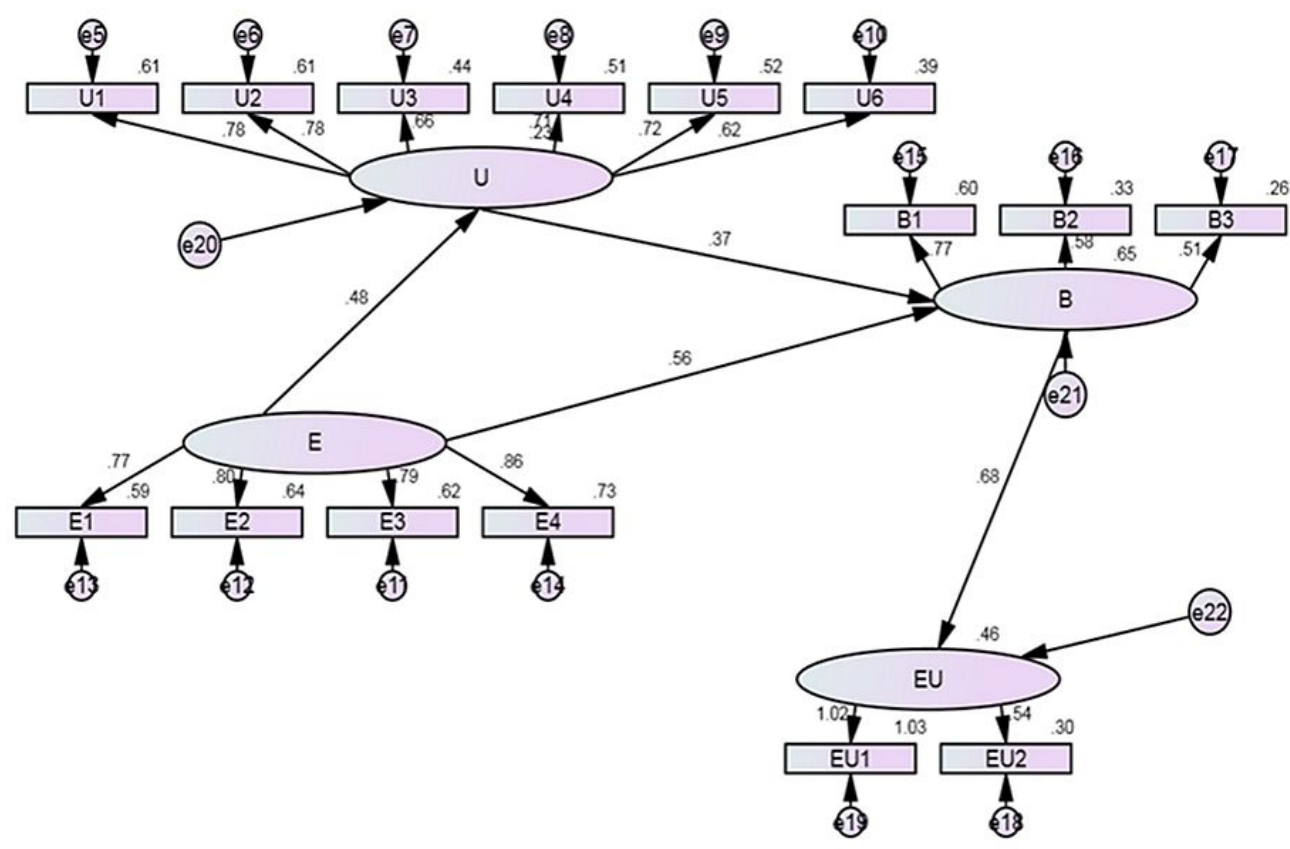

Source: own research and processing

Figure 1: The structural model for consumer attitude towards e-commerce usage.

to note that PEOU exerts a greater influence on $\mathrm{BI}$ $(\mathrm{PEOU}->\mathrm{BI}=0.56)$ than $\mathrm{PU}(\mathrm{PU}->\mathrm{BI}=0.37)$. This suggests that although the consumers find the e-commerce web application to market Udupi jasmine "useful", the application must be "easy to use". Behavioural intention exerts a significant positive influence on the actual e-commerce use $(\mathrm{BI}->\mathrm{EU}=0.68)$ suggests that the consumers 
are willing to use e-commerce in buying the GI based crop if an online web application is provided. Hence it can be inferred that, if provided with an e-commerce application to purchase the GI based crop (Udupi jasmine) online consumers are likely to accept and use it.

\section{Conclusions}

Technology Acceptance Model (TAM) has been employed, effectively and suitably, to elucidate and predict the personal acceptance of technology use. Hence successful assessment of consumers acceptance of e-commerce to purchase geographical indication-based crop using TAM shows willingness of consumers in acceptance. Assessment of TAM variables Perceived Usefulness, Perceived Ease Of Use, Behavioural Intention and E-commerce Use was found to be very high suggesting a positive response from the respondents. The SEM model fitted between PU, PEOU, BI and EU showed reasonably good model fit according to multiple SEM fit statistics. As all the values fall within the desired range it represents a good fitting model. The path diagram and the table showed that the relation between PU and PEOU is significant and positive. The analysis suggests that Behavioural Intentions of consumers will influence them into actual E-Commerce use. Behavioural Intention exerts a significant positive influence on the actual E-commerce Use (BI -> EU = 0.68) suggests that, if provided with an e-commerce application to purchase GI based crop online, consumers are likely to accept and use it. Thus, it validates the model (D'souza and Joshi, 2018) using which the web application is built.

As there is willingness among consumers in GI product online the following recommendations are suggested to boost the agricultural e-commerce segment:

- Promoteinvestmentin the agriculturalICT sector. Through the right policy-framework, improve the business environment that facilitates research, innovation, development along with investment. Public-Private Partnerships are a good example that would encourage investment in ICT infrastructure and applications. Through the right policyframeworks, development can be accelerated in open source and other technologies that would be easily available to rural small farming communities.
- Promote linkages between institutions and farming communities through ICT. An increase in globalization and liberalization of trade have immense benefits and these benefits can be used by agricultural systems. Small farmers need competence in connecting agricultural production with processing of agricultural products, marketing and the creation of grower's organizations. The total system is made up of these small domains of each agricultural disciplines. Linkages between institutions and farming communities through ICT will result in an increase in farmer's competence in agricultural production, marketing, finance and micromanagement of details that would enhance agricultural productivity.

- Enhance digital inclusion. The use of a variety of policy measures and technical means to bridge the gap between regions and groups in the country will help to promote access to the internet at a subsidized price for the rural population. Promotion in access to educational content and broadband connectivity in primary education will accelerate digital literacy among the rural population. Targeted technology information among communitybased organizations will reduce inequalities in digital literacy levels and promote the development of a workforce for the digital economy.

- Encourage e-commerce cooperation. With cross-border trade facilitation, encouraging e-commerce cooperation can strengthen agricultural e-commerce in India. E-commerce cooperation can influence existing and future e-commerce projects to use ideas and concepts that are successful. This will also eliminate the time, effort and resources required to start new e-commerce projects at rural level.

- Encourage agricultural e-commerce investment. With the evident profitability of e-commerce in different areas, promote investors to invest in agricultural e-commerce through government support system. This will encourage entrepreneurs to explore different agricultural areas that can take advantage of e-commerce. This subsequently will also attract researchers 
to delve into doing research in agricultural e-commerce. This will help the rural community-based organizations to market their produces on a larger scale.

- Promotion of GI based crops. With many crops having GI tag in India, government assistance in promoting these crops is quite essential. The government at the state level needs to form special teams to identify the communities that are involved in producing such GI crops and provide assistance to framing communities that are involved in growing these crops. Assistance can be in the form of modern agricultural techniques, use of ICT, marketing, and promotion. This will strengthen these community-based farmers in exploring new techniques that will enhance agricultural production.

Agriculture product promotion is a critical factor for e-agriculture to succeed. Promotion is the element of market mix that includes all the way a firm communicates the merits of its products and persuades its target customers to buy it. Hence, product promotion will assist the product in reaching a larger audience. Presently India has 615 geographical indication (GI) products out of which 103 belong to the agricultural sector. Consumers' willingness of using e-commerce to buy GI based products demonstrates the possibilities of promotion of such agricultural products to a wide range of consumers and organise a largely unorganized sector.

Corresponding authors

Raghavendra Prabhu

School of Information Sciences, Manipal Academy of Higher Education

Tiger Circle Road, Madhav Nagar, Manipal, Karnataka 576104, India

E-mail: raghavendra.prabhu@manipal.edu

\section{References}

[1] Agarwal, R. and Prasad, J. (1997) "The Role of Innovation Characteristics and Perceived Voluntariness in the Acceptance of Information Technologies", Decision Sciences, Vol. 28, No. 3, pp. 557-582. E-ISSN 1540-5915. DOI 10.1111/j.1540-5915.1997.tb01322.x.

[2] Aladwani, A. M. (2002) "An empirical examination of the role of social integration in system development projects", Information Systems Journal, Vol. 12, No. 4, pp. 339-353. E-ISSN 1365-2575. DOI 10.1046/j.1365-2575.2002.00133.x.

[3] Argawal, R. and Karahanna, E. (2000) "Time Flies When You're Having Fun: Cognitive Absorption and Beliefs about Information Technology Usage", Management Information Systems Quarterly, Vol. 24, No. 4, pp. 665-694. ISSN 0276-7783. DOI 10.2307/3250951.

[4] Babin, B. J. and Babin, L. (2001) "Seeking something different? A model of schema typicality, consumer affect, purchase intentions and perceived shopping value", Journal of Business Research, Vol. 54, No. 2, pp. 89-96. ISSN 0148-2963. DOI 10.1016/S0148-2963(99)00095-8.

[5] Chuttur, M. (2009 "Overview of the Technology Acceptance Model: Origins , Developments and Future Directions", Association for Information Systems, AIS Electronic Library (AISeL), All Sprouts Content, 290. [Online]. Available: http://aisel.aisnet.org/sprouts_all/290 [Accessed: 9 Aug., 2021].

[6] Cooper, D. and Schindler, P. (2016) "Business Research Methods", $12^{\text {th }}$ ed., McGraw-Hill Education. ISBN 978-0-07-352150-3.

[7] Dillon, A. and Morris, M. G. (1996) „User Acceptance of Information Technology: Theories and Models", Annual Review of Information Science and Technology, Vol. 14, No. 4, pp. 3-32. E-ISSN 1550-8382. [Online]. Available: http://hdl.handle.net/10150/105584. [Accessed: 15 Aug., 2021].

[8] D'souza, D. J. and Joshi, H. G. (2019) "E-Commerce Framework for Strategic Marketing of Udupi Jasmine", AGRIS on-line Papers in Economics and Informatics, Vol. 11, No. 1, pp. 17-26. ISSN 1804-1930. DOI 10.7160/aol.2019.110102. 
[9] D’souza, D. J. and Joshi, H. G. (2020) "Exploring the Consumers Willingness of Using E-Commerce to Purchase Geographical Indication Based Crops, a Case Study of Udupi Jasmine", AGRIS on-line Papers in Economics and Informatics, Vol. 12, No. 2, pp. 63-69. ISSN 1804-1930. DOI 10.7160/aol.2020.120206.

[10] Gefen, D. and Straub, D. (2000) "The Relative Importance of Perceived Ease of Use in IS Adoption: A Study of E-Commerce Adoption", Journal of the Association for Information Systems, Vol. 1, No. 1, pp. 1-30. E-ISSN 1536-9323. DOI 10.17705/1jais.00008.

[11] Ha, S. and Stoel, L. (2009) "Consumer e-shopping acceptance: Antecedents in a technology acceptance model", Journal of Business Research, Vol. 62, No. 5, pp. 565-71. ISSN 0148-2963. DOI 10.1016/j.jbusres.2008.06.016.

[12] Hair, J. F. Jr., Black, W. B., Babin, B. J. and Anderson, R. E. (2010) "Multivariate Data Analysis", $7^{\text {th }}$ ed., Pearson Education Limited. ISBN 10 0138132631, ISBN 13 978-0138132637.

[13] Hassan, A. Z. and Al-Alnsari, A. A. (2010), "Assessing Kuwaitis' Intention to Shop Online Using TAM", Journal of Transnational Management, Vol. 15, No. 4,pp. 293-367. E-ISSN 1547-5786, ISSN 1547-5778. DOI 10.1080/15475778.2010.525493.

[14] Johnson, V. E. (2013) "Revised standards for statistical evidence", Proceedings of the National Academy of Sciences of the United States of America, Vol. 110, No. 48, pp. 19313-19317. E-ISSN 1091-6490, ISSN 0027-8424. DOI 10.1073/pnas.1313476110.

[15] Lederer, A. L., Maupin, D. J., Sena, M. P. and Zhuang, Y. (2000) ,"The technology acceptance model and the World Wide Web", Decision Support Systems, Vol. 29, No. 3, pp. 269-282. ISSN 0167-9236. DOI 10.1016/S0167-9236(00)00076-2.

[16] Lin, J. C. C. and Lu, H. (2000) "Towards an understanding of the behavioural intention to use a web site", International Journal of Information Management, Vol. 20, No. 3, pp. 197-208. ISSN 0167-9236. DOI 10.1016/S0268-4012(00)00005-0.

[17] Marsh, H. W. and Grayson, D. (1995) "Structural equation modeling: Concepts, issues, and applications", Thousand Oaks, CA: US: Sage Publications, Inc, pp. 177-198.

[18] O'Cass, A. and Fenech, T. (2003) "Web retailing adoption: Exploring the nature of internet users Web retailing behaviour", Journal of Retailing and Consumer Services, Vol. 10, No. 2, pp. 81-94. ISSN 0969-6989. DOI 10.1016/S0969-6989(02)00004-8.

[19] Schepers, J. and Wetzels, M. (2007) "A meta-analysis of the technology acceptance model: Investigating subjective norm and moderation effects", Information and Management, Vol. 44, No. 1, pp. 90-103. ISSN 0378-7206. DOI 10.1016/j.im.2006.10.007.

[20] Schumacker, R. E. and Lomax, R. G. (2010) "A Beginner's Guide to Structural Equation Modeling", $3^{\text {rd }}$ ed. Routledge/Taylor \& Francis Group. ISBN 978-1-84169-890-8.

[21] Sekaran, U. and Bougie, R. (2016) "Research methods for business: a skill-building approach", John Wiley \& Sons. ISBN 978-1-119-26684-6.

[22] Syarifudin, G., Abbas, B. S. and Heriyati, P. (2018) "TAM Approach on E-Commerce of Aircraft Ticket Sales on Consumer Purchase Intention", $6^{\text {th }}$ International Conference on Cyber and IT Service Management. DOI 10.1109/CITSM.2018.8674357.

[23] Yang, K. and Banamah, A. (2014) "Quota sampling as an alternative to probability sampling? An experimental study", Sociological Research Online, Vol. 19, No. 1. E-ISSN 1360-7804, ISSN 1360-7804. DOI 10.5153/sro.3199.

[24] Zikmund, W. G. (2003) "Business research methods", $7^{\text {th }}$ ed., Mason, OH: Thomson/South-Western. 